\title{
3D-MODELS AS A METHOD FOR REFLECTING VOLUME AND SPATIAL PARAMETERS OF OIL-CONTAMINED SITES
}

\author{
Elvina Mukhametshina ${ }^{1, *}$ and Ibragim Aitov $^{2}$ \\ ${ }^{1}$ Industrial University of Tyumen, 628616 Nizhnevartovsk, Russian Federation \\ ${ }^{2}$ Industrial University of Tyumen, 628616 Nizhnevartovsk, Russian Federation
}

\begin{abstract}
Today oil companies are trying to solve the urgent problem associated with the low efficiency of remediation work in oil-contaminated areas. Difficulties are caused by the lack of spatially ordered ideas about where and how pollution is distributed, what is its concentration and volumetric parameters in soils. The indicated problem entails an irrational waste of finance. As a rule, the return on funds spent does not exceed $30 \%$. Obviously, the time has come to apply new approaches. We offer a technique for representing contaminants in the form of 3D models and tabular systematization of their concentrations and volumes. Scaling tabular information determines the color content of volumetric models. The described technique allows the differentiation of areas and their parts into reclamation groups. They focus on targeted use of allocated finances. Tabular systematization and spatially ordered representations of research results produce a synergistic effect. It manifests itself in obtaining a more accurate assessment of the condition of oilcontaminated sites, increasing the efficiency of restoration, the efficient use of finance.
\end{abstract}

\section{Introduction}

The study analyzed 15 scientific publications included in the Scopus database and Web of Science. In the works, various methods and types of land reclamation were proposed to maintain environmental safety in the construction and reconstruction of oil and gas fields, in the development of mineral deposits, in the extraction of mineral resources, etc. [1-5]. However, the articles we have analyzed do not propose a methodology for creating three-dimensional models that allow us to show in color and volume the content of oil products, chlorides, and the concentration of acidity in soils for the most effective reclamation.

In the analyzed works, the authors propose various chemical reagents for reclamation works, such as, for example, industrial humates for the reclamation of oilcontaminated peat soils [6]. Also, methods of cleaning and reclamation of soils contaminated with oil and oil products have been proposed [7]. Some articles describe the features of biological reclamation of oilcontaminated and technologically saline soils [8], many assess the ecological condition of soils [9], and analyze the basics of environmental safety and land reclamation, as well as environmental protection [10-13].

\section{Methods}

\subsection{Correction of the location, boundaries and description of oil-contaminated areas listed on the balance sheet of oil companies}

Their topographic survey and photographing were carried out. Division of sections into parts: allotments and parcels. Creation of cartographic schemes and other graphic images of sites and their parts. Formation of a hierarchical system of 3 levels for each site. 1 smallest level - parcel, as one of the four layers within the boundaries of the allotment; Level 2 - selection of a site with a set of four parcels; Level 3 - the entire site in the aggregate of allotments and parcels (fig. 1).

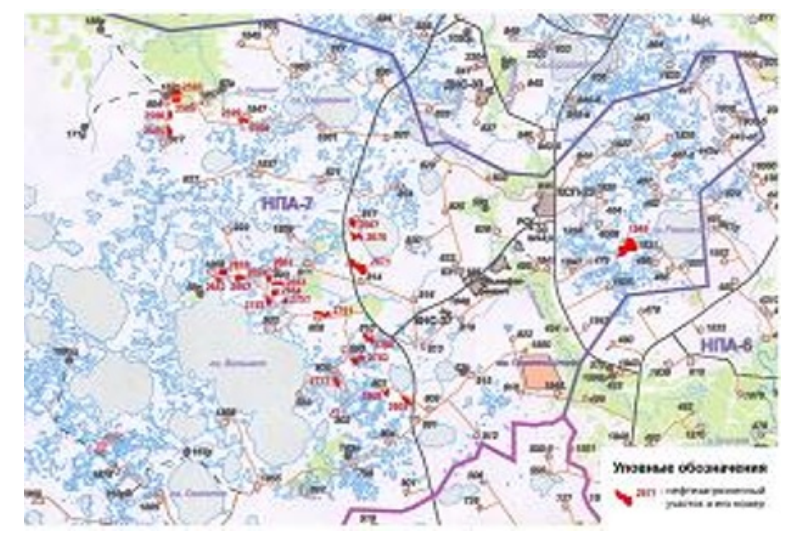

Fig. 1. Map of land plots.

\footnotetext{
* Corresponding author: muhametshina.elwina2015@yandex.ru
} 
Table 1. Data of Quantitative Chemical Analysis of samples from the site 2.7.2598.

\begin{tabular}{|c|c|c|c|c|c|}
\hline \multirow{4}{*}{$\begin{array}{l}\text { The number of } \\
\text { sampling site }\end{array}$} & \multirow{4}{*}{$\begin{array}{l}\text { Sampling depth, } \\
\text { cm }\end{array}$} & \multicolumn{4}{|c|}{ The determined indicator } \\
\hline & & \multirow{2}{*}{\multicolumn{2}{|c|}{\begin{tabular}{|c|} 
The oil products \\
Contents
\end{tabular}}} & \multirow{3}{*}{$\begin{array}{c}\text { The chlorides } \\
\text { Contents }\end{array}$} & \multirow{3}{*}{$\begin{array}{r}\text { The acidity } \\
\text { Contents }\end{array}$} \\
\hline & & & & & \\
\hline & & $\mathrm{mg} / \mathrm{kg}$ & $\%$ & & \\
\hline \multirow{4}{*}{83} & $0-10$ & 060661 & 6.1 & $3378(0.34)$ & 5.5 \\
\hline & $20-30$ & 118130 & 11.8 & $2549(0.25)$ & 5.6 \\
\hline & $40-60$ & 050700 & 5.1 & $7345(0.73)$ & 4.8 \\
\hline & $90-110$ & 046667 & 4.7 & $8590(0.86)$ & 5.4 \\
\hline \multirow{4}{*}{84} & $0-10$ & 780176 & 78.0 & $1228(0.12)$ & 4.9 \\
\hline & $20-30$ & 116316 & 11.6 & $1775(0.18)$ & 3.4 \\
\hline & $40-60$ & 109206 & 10.9 & $3900(0.39)$ & 3.3 \\
\hline & $90-110$ & 020563 & 2.1 & $2577(0.27)$ & 3.1 \\
\hline \multirow{4}{*}{85} & $0-10$ & 720100 & 72.0 & - & - \\
\hline & $20-30$ & 357100 & 35.7 & $3187(0.32)$ & 4.6 \\
\hline & $40-60$ & 065810 & 6.6 & $4650(0.46)$ & 3.8 \\
\hline & $90-110$ & 027550 & 2.8 & $10066(1.01)$ & 3.5 \\
\hline \multirow{4}{*}{86} & $0-10$ & 776700 & 77.7 & - & - \\
\hline & $20-30$ & 186100 & 18.6 & $9570(0.96)$ & 4.7 \\
\hline & $40-60$ & 018190 & 1.8 & $24800(2.48)$ & 3.7 \\
\hline & $90-110$ & 015120 & 1.5 & $22500(2.25)$ & 3.3 \\
\hline
\end{tabular}

\subsection{Soil sampling at sites. Quantitative chemical analysis}

We carried out sampling from parcels (depths) from 0-10 $\mathrm{cm}, 20-30 \mathrm{~cm}, 40-60 \mathrm{~cm}, 90-110 \mathrm{~cm}$ (the last parcel is inaccessible). The results of the quantitative chemical analysis are shown in table 1.

\subsection{Registration of the results of quantitative chemical analysis in tabular form}

Scaling and coloring of $\mathrm{pH}$ values and the content of oil pollution, chlorides. Calculation of the volumes of deposits, deep seams and pollution.

Table 2. The oil pollution scale.

\begin{tabular}{|c|c|}
\hline Oil content, $\%$ & Color \\
\hline $0-1.0$ & green \\
\hline $1.1-3.0$ & yellow \\
\hline $3.1-6.0$ & orange \\
\hline $6.1-10.0$ & light brown \\
\hline $10.1-15.0$ & dark brown \\
\hline $15.1-25.0$ & pink \\
\hline $25.1-40.0$ & light red \\
\hline$>40.0$ & dark red \\
\hline
\end{tabular}

\subsection{Creation of 3D-models of plots with the display of each parcel in volume and color}

The 3D model in color reflects the $\mathrm{pH}$, the concentration of chlorides and the volume of petroleum products in each parcel of the site. As a rule, the number of parcels within the boundaries of a single section does not exceed 4; the lower parcel is not deeper than $2.0 \mathrm{~m}$ (in our case, $1.1 \mathrm{~m}$ ). The upper three parcels of soil are available for remediation: a) - 0-10 cm, b) - 10-30 cm, c) - 30-60 cm; d) $-60-110 \mathrm{~cm}$ (inaccessible).

\subsection{Distribution of sites and their parts to reclamation groups}

a) plots or parts thereof where biological reclamation is required;

b) plots or parts thereof where biological reclamation is not required;

c) plots or parts of them where it is currently impossible to achieve the required results during biological reclamation due to the lack of necessary or insufficient existing technologies;

d) sections or parts of them where biological restoration is temporarily impractical due to the high probability of their re-contamination due to insufficient operational reliability of pipelines.

\section{Results and Discussion}

We propose the use of 3D-models of oil-contaminated sites for these purposes, as well as tables with which you can calculate and determine the qualitative and quantitative data needed for reclamation.

The list of factors affecting the condition of each site and subject to accounting can be significant, but among the mandatory three should be distinguished: 1) the density of soil layers, 2) the content of petroleum products and 3) chlorides. They are more often than others are limiting for organisms, affect the activity and migration of many substances. To adequately determine the condition of the contaminated site, it is necessary to understand the distribution of the indicators of the above three factors not only by area, but also in depth. Therefore, it is necessary to build three-dimensional models (3D).

We will show the application of the indicated models and tables by the example of one of the oil-contaminated land plots of the Samotlor field under conditional registration number 2.7.2598. (fig. 2). 


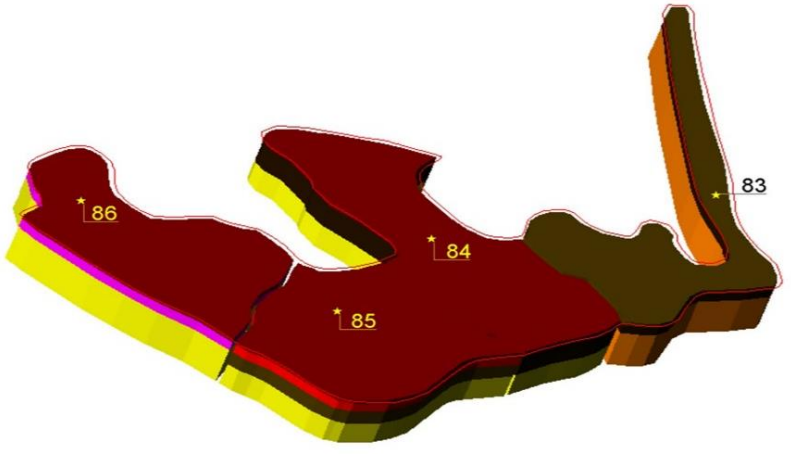

Fig. 2. The 3D-model of oil pollution of the site 2.7. 2598.

Previously, a table was created with the results of quantitative chemical analysis, summarizing data on parts of the site (table 1).

Then, to colorize the values, tables with color scales for the content of oil products, chlorides and acidity concentration are compiled (table 2, 3, 4) [15].

An analysis of open sources showed that there are three main degrees of oil pollution of soils:

1) weak - up to $10 \%$;

2) average - from 10 to $40 \%$;

3) strong - more than $40 \%$. [16].

Low pollution sharply reduces productivity and leads to the death of about $1 / 2$ of the vegetation. With medium pollution, the stand and shrubs die completely within 10 years. Strong oil pollution completely destroys the phytocenosis in the period up to 1 year [17].

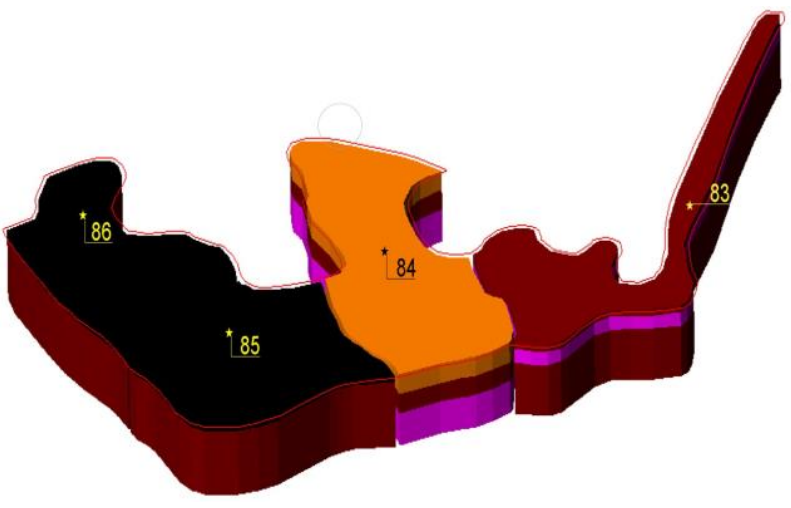

Fig. 3. The 3D-model chloride contamination of the site 2.7. 2598.

Graphic images of the surveyed areas are divided into zones (allotments and parcels) more or less uniform in some respects (features of relief, moisture, soil, vegetation, spilled oil or oil crust, etc.). As a rule, the area of such zones does not exceed 0.2 hectares [18].

Table 3. The chloride contamination scale, g/ $\mathrm{kg}$.

\begin{tabular}{|c|c|c|}
\hline $\begin{array}{c}\text { Parameter of chloride } \\
\text { contamination } \mathbf{g} / \mathbf{k g}\end{array}$ & $\begin{array}{c}\text { Pollution } \\
\text { degree }\end{array}$ & Color \\
\hline$<0.2$ & very weak & green \\
\hline $0.21-1.0$ & weak & yellow \\
\hline $1.1-2.0$ & average & orange \\
\hline $2.1-3.0$ & strong & pink \\
\hline$>3.0$ & very strong & red \\
\hline
\end{tabular}

Critical concentration-the concentration of chlorides, under the action of which there are initial signs of harmful effects: changes in the development of the organism, its growth or biomass are reduced by $20-35 \%$. For grasses-0.07-0.15 g / kg, for trees-0.2-0.3 g / kg.

Pathological concentration-the concentration of chlorides, at which tissue necrosis occurs, the death of organs and individual plants, organisms; growth and biomass of plants are reduced by $40-70 \%$. For grasses$0.2-0.3 \mathrm{~g} / \mathrm{kg}$, for trees-0.4-0.6 g / kg.

Lethal concentration-the concentration of chlorides, at which the death of more than $50 \%$ of organisms occurs, the growth or biomass of plants decreases by more than $75 \%$. For grasses- $0.4 \mathrm{~g} / \mathrm{kg}$, for trees- $1.0 \mathrm{~g} /$ $\mathrm{kg}$. at a concentration of more than $2.0 \mathrm{~g} / \mathrm{kg}$, mainly halophytic plants take root and survive [19].

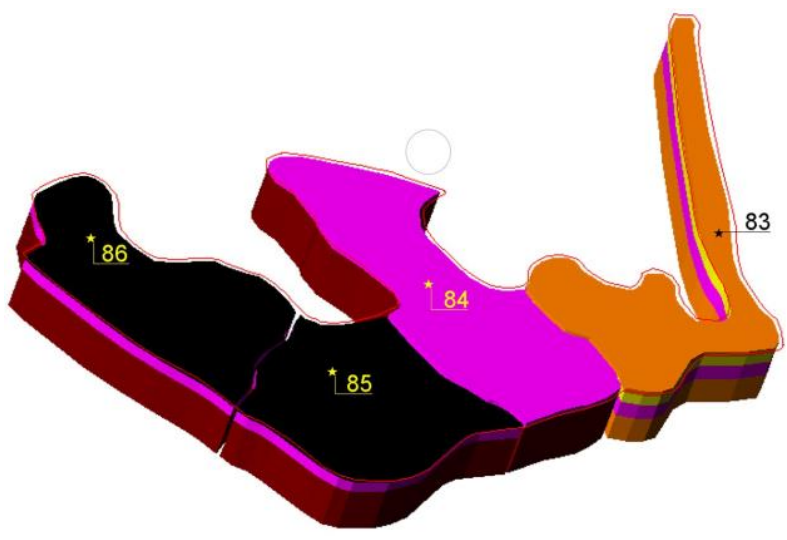

Fig. 4. The 3D-model soil acidity of the site 2.7. 2598.

Similarly to table 2 , the data on the chloride content and acidity concentration in the soils of the land plot were processed. Tables on color scaling of pollution are presented below (table 4).

Table 4. The soil acidity scale.

\begin{tabular}{|c|c|c|}
\hline $\begin{array}{c}\text { Parameter of soil } \\
\text { acidity }\end{array}$ & Degree of soil acidity & Color \\
\hline$<4$ & strong acid & red \\
\hline $4.5-5.0$ & medium acid & pink \\
\hline $5.1-5.5$ & slightly acidic & orange \\
\hline $5.6-6.0$ & close to neutral & yellow \\
\hline $6.1-7.0$ & neutral & brown \\
\hline$>7.0$ & alkaline & green \\
\hline
\end{tabular}

The bulk of the soils of the region has a predominantly slightly acidic reaction in the range-zone 4.9-5.5 $\mathrm{pH}$, podzols-3.5-4.5; upper peatlands - 2.9-4.1; transitional-5.0-7.2; lowland-5.0-7.3; meadow soils-4.56.5. Optimal conditions for the development of soil organisms spreading petroleum products, intensification of the circulation of substances in biogeocenoses are characterized by acidity from 6.0 to 7.5 . In conditions of lower $\mathrm{pH}$, the speed and completeness of the biodegradation processes of oil is sharply reduced. Increased soil acidity negatively affects the germination of seeds of tree and shrub species, the growth and development of seedlings and seedlings, less often on the productivity of the forest [20]. 
Table 5. The spatial parameters of the site № 2.7.2598.

\begin{tabular}{|c|c|c|c|c|c|c|}
\hline \multirow{2}{*}{ Location } & \multirow{2}{*}{$\begin{array}{c}\text { Area of the } \\
\text { zone, } \mathbf{m}^{2}\end{array}$} & \multicolumn{4}{|c|}{ The volume of layers, $\mathrm{m}^{3}$} & \multirow{2}{*}{ Total, $\mathbf{m}^{3}$} \\
\hline & & $\mathrm{a}(0.1 \mathrm{~m})$ & $\mathrm{b}(0.2 \mathrm{~m})$ & $\mathrm{c}(0.3 \mathrm{~m})$ & $\mathrm{d}(0.5 \mathrm{~m})$ & \\
\hline 83 & 1344.172 & 134.417 & 268.834 & 403.252 & 672.086 & 1478.589 \\
\hline 84 & 1749.206 & 174.921 & 349.841 & 524.762 & 874.603 & 1924.127 \\
\hline 85 & 1498.700 & 149.870 & 299.740 & 449.610 & 749.350 & 1648.570 \\
\hline 86 & 1410.145 & 141.014 & 282.029 & 423.043 & 705.072 & 1551.158 \\
\hline Subtotal & 6002.223 & 600.222 & 1200.444 & 1800.667 & 3001.111 & 6602.444 \\
\hline
\end{tabular}

Table 6. The volume content of oil product residues in the soil of the site № 2.7.2598.

\begin{tabular}{|c|c|c|c|c|c|}
\hline \multirow{2}{*}{ Location } & \multicolumn{3}{|c|}{ The volume of residues of oil products, $\mathbf{~ m}^{\mathbf{3}}$} & \multirow{2}{*}{ Total, $\mathbf{~ m}^{\mathbf{3}}$} \\
\cline { 2 - 5 } & $\mathbf{a}(\mathbf{0 . 1} \mathbf{~ m})$ & $\mathbf{b}(\mathbf{0 . 2} \mathbf{~ m})$ & $\mathbf{c}(\mathbf{0 . 3} \mathbf{~ m})$ & $\mathbf{d} \mathbf{~ m})$ & 3.17 \\
\hline 83 & & $3.17(0.012)$ & & & 23.42 \\
\hline 84 & $13.64(0.078)$ & $4.06(0.012)$ & $5.72(0.011)$ & & 21.49 \\
\hline 85 & $10.79(0.072)$ & $10.7(0.04)$ & & & 16.21 \\
\hline 86 & $10.96(0.078)$ & $5.25(0.019)$ & & & $\mathbf{6 4 . 2 9}$ \\
\hline Subtotal & $\mathbf{3 5 . 3 9}$ & $\mathbf{2 3 . 1 8}$ & $\mathbf{5 . 7 2}$ & & \\
\hline
\end{tabular}

Then it was required to create tables that visually reflect data on the total area and volume of the site, as well as its parts and layers (table 5).

The following table was compiled to determine the volumetric residues of petroleum products requiring remediation work (table 6).

Similar tables are created to determine the volumes of parts of the site with chlorides and acidity, requiring remediation measures (table 7,8 ).

Of all anions, chlorides have the greatest migration ability, which is explained by their good solubility, weakly expressed ability to sorption by suspended solids. Background values of chloride content in the soils of the region are mainly in the range of $0.01-0.05 \%(0.1-0.5 \mathrm{~g} /$ $\mathrm{kg})[21]$.

To determine the volume residues of petroleum products that should be processed, convert the percentage to a fraction of the unit. Then multiply as in table 8 . Get the desired volume values.

\section{Conclusions}

The results obtained by us during the work show that we have achieved our goal, because our proposed technique allows us to present the parameters of the oilcontaminated area in three-dimensional and tabular form for a more accurate assessment of the state of oilcontaminated areas [22]. An accurate assessment helps to carry out effective remediation, allowing land to be turned over to environmental services.

The surveyed areas and their parts, taking into account the reclamation requirements, can be divided into groups: 1) requiring technical and biological reclamation; 2) requiring only biological reclamation; 3) not requiring re-cultivation, because vegetation can recover independently [23]. 3D models and determination of the volume content of post-accident residues of petroleum products, chlorides and acidity concentration provided significant assistance in this division.

Table 7. The volume content of chloride in the soil of the site № 2.7.2598.

\begin{tabular}{|c|c|c|c|c|c|}
\hline \multirow{2}{*}{ Location } & \multicolumn{4}{|c|}{ The volume of chloride content, $\mathbf{m}^{\mathbf{3}}$} & \multirow{2}{*}{ Total, $\mathbf{~ m}^{\mathbf{3}}$} \\
\cline { 2 - 5 } & $\mathbf{a}(\mathbf{0 . 1} \mathbf{~ m})$ & $\mathbf{b}(\mathbf{0 . 2} \mathbf{~ m})$ & $\mathbf{c}(\mathbf{0 . 3} \mathbf{~ m})$ & $\mathbf{d}(\mathbf{0 . 5} \mathbf{~ m})$ & \\
\hline 83 & & & & & \\
\hline 84 & & & & & \\
\hline 85 & & & & & \\
\hline 86 & & & $1.049(2.48)$ & $1.586(2.25)$ & 2.609 \\
\hline Subtotal & & & $\mathbf{1 . 0 4 9}(\mathbf{2 . 4 8})$ & $\mathbf{1 . 5 8 6}(\mathbf{2 . 2 5})$ & $\mathbf{2 . 6 0 9}$ \\
\hline
\end{tabular}

Table 8. The volume content of acid concentration in the soil of the site № 2.7.2598.

\begin{tabular}{|c|c|c|c|c|c|}
\hline \multirow{2}{*}{ Location } & \multicolumn{3}{|c|}{ The volume of acidity, $\mathbf{~ m}^{\mathbf{3}}$} & \multirow{2}{*}{ Total, $\mathbf{m}^{\mathbf{3}}$} \\
\cline { 2 - 5 } & $\mathbf{a}(\mathbf{0 . 1} \mathbf{~ m})$ & $\mathbf{b}(\mathbf{0 . 2} \mathbf{~ m})$ & $\mathbf{c}(\mathbf{0 . 3} \mathbf{~ m})$ & $\mathbf{d}(\mathbf{0 . 5} \mathbf{~ m})$ & \\
\hline 83 & & & $1.935(4.8)$ & & 1.935 \\
\hline 84 & $1.085(4.9)$ & $1.189(3.4)$ & $1.731(3.3)$ & $2.711(3.1)$ & 6.716 \\
\hline 85 & & $1.378(4.6)$ & $1.483(3.8)$ & $2.622(3.5)$ & 5.483 \\
\hline 86 & & $1.325(4.7)$ & $1.565(3.7)$ & $2.326(3.3)$ & 5.216 \\
\hline Subtotal & $\mathbf{1 . 0 8 5}$ & $\mathbf{3 . 8 9 2}$ & $\mathbf{6 . 7 1 4}$ & $\mathbf{7 . 6 5 9}$ & $\mathbf{1 9 . 3 5}$ \\
\hline
\end{tabular}




\section{References}

1. S. Davydova, V. Tagasov, Environmental pollution by oil and oil products (RUDN, Moscow, 2006)

2. S. Kulikov, N. Patrin, Remediation of oilcontaminated landsб Russia young: advanced technologies in industry. 3, 2013

3. R. Scopina, E. Panov, Reclamation of disturbed lands (Bibliographer, Moscow, 1984)

4. Ch. Vyalih, S. Shulga, Recultivation of lands (The Center. Chernozem, Voronezh, 1980)

5. T. Fedoseva, Recultivation of lands (Ear, Moscow, 1977)

6. G. Kolbasov, M. Rozanova, Use of industrial humates for reclamation of oil-contaminated peat soils (MGU, Moscow, 2011)

7. D. Stom, D. Potapov, Method of purification and reclamation of soils contaminated with oil and oil products. 19, General issues of chemical technology, 2005

8. S. Lushnikov, N. Mitrofanova, and N. Tereschenko, Features of biological reclamation of oil-contaminated and technogenic-saline soils, Ecology and industry of Russia. 6, 2005

9. A. Muravev, B. Korryev, and A. Lyzndzberg, Assessment of the ecological state of the soil (Christmas + , SPb , 1999)

10. A. Bannikov, Fundamentals of ecology and environmental protection (Ear, Moscow, 1999)

11. L. Astanin, K. Blagosklonov, Nature protection (Ear, Moscow, 1984)

12. L. Motorina, A. Savich, Ecological basis of land reclamation (Science, Moscow, 1985)

13. N. Cherkasova, Ecological basis of reclamation (Science, Moscow, 1985)

14. B. Chyzhov, V. Kozina, Forest and oil of KhantyMansi Autonomous Okrug (Yu. Mandriki, Tyumen, 1998)

15. Regional standard "Permissible residual content of oil and oil products in soils after reclamation and other restoration works on the territory of the KhantyMansiysk Autonomous Okrug-Ugra", approved by the resolution of the government of the Khanty-Mansiysk Autonomous Okrug - Ugra dated December 10, 2004 No. 466-p.

16. K. Lopatin, State of environment and natural resources in Nizhnevartovsk district in 2003-2005 (Yuogorski, Nizhnevartovsk, 2006)

17. I. Aitov, E. Kozelkova, and E. Kuznecova, Typical types of negative impacts on license areas of oil companies in the area of cluster sites (Yuogorski, Nizhnevartovsk, 2006)

18. L. Dobrinski, V. Plotnikov, Ecology of KhantyMansi Autonomous Okrug (SoftDesign, Tyumen, 1997)

19. M. Kazanceva, S. Gashev, Monitoring studies at the site of an emergency oil spill in the taiga zone of Western Siberia. 1, 2000

20. M. Kazanceva, M. Cherkasova, and E. Talipova, Formation of vegetation cover at the site of oil pollution remediation in the sub-taiga of Western Siberia. 6, 2011.
21. J. P. Grime. Benefits of plant diversity to ecosystems: immediate, filter and founder effects. 6, 1998.

22. L. R. Holdridge. Life zone ecology. Life zone ecology. 3, 1967.

23. J. R. McLaren, R. Turkington. Ecosystem properties determined by plant functional group identity. Journal of Ecology. 98(2), 2009. 